\title{
U.S. State-Supported Dental Schools: Financial Projections and Implications
}

\author{
Howard L. Bailit, D.M.D., Ph.D.; Tryfon J. Beazoglou, Ph.D.; Allan J. Formicola, D.D.S.; \\ Lisa A. Tedesco, Ph.D.; L. Jackson Brown, D.D.S., Ph.D.; Richard G. Weaver, D.D.S.
}

Abstract: This article examines the impact of financial trends in state-supported dental schools on full-time clinical faculty; the diversity of dental students and their career choices; investments in physical facilities; and the place of dentistry in research universities. The findings of our study are the following: the number of students per full-time clinical faculty member increased; the three schools with the lowest revenue increases lost a third of their full-time clinical faculty; more students are from wealthier families; most schools are not able to adequately invest in their physical plant; and more than half of schools have substantial $\mathrm{NIH}$-funded research programs. If current trends continue, the term "crisis" will describe the situation faced by most dental schools. Now is the time to build the political consensus needed to develop new and more effective strategies to educate the next generation of American dentists and to keep dental education primarily based in research universities. The future of the dental profession and the oral health of the American people depend on it.

Dr. Bailit is Research Associate, Department of Community Dentistry, Columbia University; Dr. Beazoglou is Professor, Department of Pediatric Dentistry, University of Connecticut; Dr. Formicola is Professor, Center for Community Health Partnerships, Columbia University; Dr. Tedesco is Professor, Department of Periodontics, Prevention, and Geriatrics, University of Michigan; Dr. Brown is Associate Executive Director, American Dental Association; and Dr. Weaver is Acting Director, Center for Educational Policy and Research, American Dental Education Association. Direct correspondence and requests for reprints to Dr. Howard Bailit, Department of Community Medicine, School of Medicine, University of Connecticut, 260 Farmington Avenue, Farmington, CT 06030; 860-679-5487 phone; 860-679-5463 fax; bailit@nso1.uchc.edu.

This work was funded, in part, by a grant from the Josiah Macy, Jr. Foundation.

Key words: education, finances, faculty and student trends, research universities

Submitted for publication 9/15/05; accepted 11/28/05

$\mathrm{T}$ he financial challenges facing the nation's thirty-six state-supported dental schools have received considerable attention. Based on 1990 to 2000 data, state support for dental schools has not kept up with inflation. ${ }^{1,2}$ This problem is made more acute by the fact that the incomes of community practitioners are growing twice as fast as those of dental school clinical faculty. ${ }^{1}$ From more recent data (2002), the financial problems of state-supported dental schools are getting worse as a result of the national economic slow-down starting in 2000 and the large shortfalls in state budgets. This has led many states to further reduce budget increases for higher education, including dental schools. ${ }^{3}$

Some recent articles suggest that declining state support and increasing disparities in faculty and practitioner incomes may be linked to some adverse trends in dental school operations. The number of vacant clinical full-time faculty positions has increased, many faculty are leaving academia for private practice, and student debt at graduation has grown. ${ }^{4,5}$ Many have called these problems a crisis or at least a pending crisis. Yet, to date, schools continue to attract and graduate large numbers of students, and both schools and students are able to meet the requirements of external accrediting and certifying agencies.

Of course, even if the current financial problems have not reached the crisis stage for most schools, another ten years of slow-growing or declining state budgets may lead to major operational problems that will be considered a crisis. Some schools, for example, may be forced to reduce the number of full-time faculty to the point that their accreditation status is threatened.

Of perhaps greater concern are the long-term strategic implications of these financial trends to dental education and, in turn, to the profession. These concerns have had limited discussion in the literature. ${ }^{4}$ Ultimately, they relate to two critical outcomes: first, the capacity of dental schools to recruit and graduate adequate numbers of qualified dental students and residents to meet the national demand for dental services; and second, the capacity of dental schools to meet the academic missions of the parent research university with respect to faculty scholarship.

The first outcome is well understood and does not need further discussion, but the second outcome

Reprinted from Journal of Dental Education 2006;70(3):246-57. 
may not be as obvious. It is important to understand that major research universities have as a primary and explicit mission the generation of new scientific knowledge. All graduate and professional schools and colleges within research universities, including dental schools, are obligated to meet this mission. If the majority of dental schools do not have the resources to do so, the status of dentistry as a learned, self-regulating profession, comparable to law and medicine, is threatened and eventually may diminish. Academic scholarship requires that dental schools have adequate numbers of full-time basic science and clinical faculty who have the training and resources (e.g., time, space, research funds, and personal income) needed to generate new scientific knowledge related to the biomedical, clinical, social, and educational sciences. As noted by Dr. Robert Anderton, past president of the American Dental Association (ADA), without an education system primarily based in research universities, the dental profession can not expect to maintain the high occupational social status and financial rewards that it now enjoys. ${ }^{6}$

The growing awareness of these larger strategic issues by the profession's leadership is encouraging. Several well-known and respected educators and practitioners have formed an association, the Santa Fe Group, to address the future of dental education. ${ }^{7}$ Likewise, the ADA, in close cooperation with the American Dental Education Association (ADEA), has held a series of educational summits to examine the financial problems of dental schools. These summits have led the ADA to initiate a national effort to raise a substantial endowment to assist dental schools financially. ${ }^{8}$ Another landmark effort to address this issue is seen in the 1999 ADEA report entitled "Report of the AADS Presidential Task Force on Future Dental School Faculty." This report clearly and forcefully articulates the financial problems faced by dental schools in recruiting full-time clinical faculty. ${ }^{9}$

The goal of this article is to explore the current and future operational and strategic challenges facing state-supported dental schools. (A separate article, in preparation, will examine the financial status of private and private, state-related dental schools.) The specific objectives are to:

1. examine selected financial trends from 1990 to 2002 and determine their impact on school operations;

2. project past financial trends to the next ten-year period (2005 to 2015) and assess their likely effect on school operations; and
3. assess the effects of past and projected financial trends on the strategic challenges facing dental education and the dental profession.

\section{Methods}

\section{Research Design}

Financial trends (1990 to 2002) in three important areas of dental school operations are presented in relation to selected outcomes: 1) differences in clinical faculty and community practitioner incomes and the recruitment and retention of full-time clinical faculty; 2) the total cost of four years of dental school and the diversity of dental students and their career choices; and 3) investment in physical facilities. The associations between financial trends and selected operational outcomes were inferred associations. With aggregate data available from thirty-six state-supported dental schools, it was impossible to prove that these were direct cause and effect relationships.

The trends for 1990 to 2002 were projected statistically to the next ten-year period (2005 to 2015). The likelihood of the projected trends and their possible impact on the operations of state-supported dental schools are discussed.

The impact of declining state budgets on a strategic outcome - the place of dentistry in research universities - was also investigated. This issue was assessed by looking at trends in the number of dental schools in top-ranked research universities and the distribution of NIH research grants awarded to dental schools in 2003.

The general model for the associations between the independent and dependent (outcomes) variables is presented in Table 1. There were three sets of independent variables; each was related to a specific set of intermediate operational outcomes. In turn, the intermediate outcomes were related, in aggregate, to a long-term strategic outcome.

\section{Data Sources}

The primary data on dental education came from the ADA surveys of predoctoral dental education, 1990/1 to 2002/3, and the ADEA survey of faculty salaries. ${ }^{10,11}$ While there are significant data limitations, these surveys provide the best available estimates of dental school financial operations, faculty salaries and qualifications, student tuition/fees, and physical plant expenditures. Data on student 


\section{Table 1. General model of relationships between independent and dependent variables}

\begin{tabular}{|c|c|c|}
\hline \multirow[t]{2}{*}{ Independent Variables } & \multicolumn{2}{|c|}{ Dependent (Outcome Variables) } \\
\hline & Intermediate (Operational) & Long-Term (Strategic) \\
\hline $\begin{array}{l}\text { Income differences between full-time (FT) } \\
\text { clinical faculty and private practitioners }\end{array}$ & $\begin{array}{l}\text { 1. FT clinical faculty positions/DDSE } \\
\text { 2. \% PT to FT clinical faculty positions } \\
\text { 3. Unfilled FT clinical faculty positions } \\
\text { 4. \% Board-certified/qualified FT clinical } \\
\text { faculty } \\
\text { 5. \% FT clinical faculty with PhD degrees }\end{array}$ & \\
\hline $\begin{array}{l}\text { Student four-year expenses for dental } \\
\text { education }\end{array}$ & $\begin{array}{l}\text { 1. \% entering students from families } \\
\text { with high and low parental incomes } \\
\text { 2. \% underrepresented minority students } \\
\text { 3. Career choice of graduates related to } \\
\text { level of debt }\end{array}$ & $\begin{array}{l}\text { Capacity to Meet Scholarship } \\
\text { Mission of Research University: } \\
\text { 1. Trends in numbers of dental } \\
\text { schools in top tier research } \\
\text { universities } \\
\text { 2. Percentage of faculty with } \\
\text { NIH grant }\end{array}$ \\
\hline Investment in physical plants & $\begin{array}{l}\text { 1. Level of investment relative to } \\
\text { consumer price index } \\
\text { 2. Level of investment compared to } \\
\text { state-funded medical schools }\end{array}$ & \\
\hline
\end{tabular}

debt, demographics, and career plans were taken from ADEA's annual senior survey. ${ }^{12}$ Data on the 1990 to 2002 income of dentists in private practice came from the annual ADA survey of dental practice. ${ }^{13}$ Data on the investment of state-supported medical schools in their physical plant for the period 1990 to 2002 came from the Association of American Medical Colleges. ${ }^{14}$ The position of dental schools in research universities came from the Carnegie Foundation, ${ }^{15}$ and research grant awards to dental schools from the National Institutes of Health $(\mathrm{NIH})$ were from the NIH website. ${ }^{16}$

Since the focus of this article is state-supported dental schools, most of the analyses were for the thirty-six schools in this category. Some results derived from secondary sources and include data from all dental schools (fifty-four to fifty-six, depending on the year). The tables and text indicate the types of dental schools included in each analysis.

\section{Independent Variable Measurement}

Income. The income used for full-time faculty salaries was the base or guaranteed annual salary provided by the dental school. It did not include income generated from faculty practices within the dental school. Nash and Brown estimated that the average amount of earnings from on-site faculty practices in 2002 was $\$ 13,650 .{ }^{17}$ Clinical faculty income did not include fringe benefits. A few schools allow faculty to work in private practices in the community; this compensation is not reported in the faculty income survey. As such, the average income of fulltime clinical faculty in state-supported schools is underestimated by a small amount.

Full-time clinical faculty income was for the rank of associate professor. This is a mid-level rank, and there are large numbers of clinical faculty at the instructor and assistant professor levels and fewer at the full professor level. Using the incomes of associate professors gives a more accurate picture of the faculty and practitioner income difference than using the average income of all clinical faculty. The latter value is heavily weighted by faculty at the rank of instructor and assistant professor.

The incomes of general dentists and specialists are presented separately because of well-established differences. In the average dental school, 50 percent of faculty are specialists. In contrast, only 20 percent of community practitioners are specialists. The income data on owner dentists in the private practice of general and specialty dentistry combines dentists in both part- and full-time practice. Since about 25 percent of dentists claim to work less than thirty-two hours a week, the cut-off point between part- and full-time practice (the difference between the income reported in the ADA surveys and the actual income of private practitioners in full-time practice) is unknown but is probably substantially higher. Thus, practitioner 
and faculty income were not strictly comparable, and there was no simple way to adjust these data to make them equivalent. Overall, practitioner income data probably underestimate, to a modest degree, the income of full-time dentists.

Education Costs. The costs of four years of dental education included tuition, fees, books, lab charges, travel, and room and board. In state-supported dental schools, tuition and fees are usually lower for resident (in-state) versus nonresident (outof-state) students.

Physical Plant Expenditures. To examine expenditures for dental school physical plant operations, data were presented on average annual expenditures from 1990 to 2002, controlling for inflation. Physical plant operational costs included administration, security, maintenance, custodial services, utilities, and renovations (from operating budgets). They did not include capital investments in facilities.

\section{Projections}

Ordinary least squares regressions were used to determine the rate of increase in general dentistry and specialty faculty salaries and practitioner incomes and the four-year costs of a dental education per student for the period 1990 to 2002 . The resulting regression coefficients were used to make projections for the period 2005 to 2015.

This projection method assumes that the average rate of increase in incomes from 1990 to 2000 will continue for the 2005 to 2015 period. This is probably a conservative assumption for private practitioners, since the dentist to population ratio is getting smaller (fewer dentists per 100,000 people), and government analysts project that the demand (expenditures) for dental care will increase 5.6 percent annually from 2005 to $2013 .{ }^{18}$ Further, dentist incomes are unlikely to be adversely affected by future reductions in the rate of growth of Medicare or Medicaid, and to date, the impact of managed care on dental practice is very limited, except in some local markets. ${ }^{19}$ Of course, major macroeconomic changes such as a severe economic recession/depression could reduce demand for dental care and, in turn, dentists' incomes. These macroeconomic issues are difficult to predict and are beyond the scope of this article.

The income projections for faculty were based on trends for the past ten years. If the current system of dental education continues, it is unlikely that new sources of revenue will become available in the next ten years to increase clinical faculty income at the same rate as community practitioner income. Indeed, the annual faculty salary growth rate of 3.4 percent a year used in the projections may be overly optimistic.

The projections for the total cost of four years of dental education were also based on trends for the past ten years. Again, unless state-supported schools find new sources of revenue, it is likely that the rate of increase for the past ten years will continue for the next ten.

\section{Dependent (Outcome) Variable Measurements}

Faculty Recruitment and Retention. To assess the impact of greater differences in faculty and practitioner income on dental school operations, five outcomes were examined. They related to the schools' major (faculty-related) options for dealing with lesscompetitive clinical salaries: 1) reduce the number of full-time clinical faculty relative to the number of dental students; 2) substitute less expensive parttime for full-time positions; 3 ) have more open or unfilled positions; 4) recruit more full-time clinical faculty who are not board-certified or -qualified; and 5) recruit more full-time clinical faculty who do not have advanced scientific degrees (i.e., Ph.D.) needed to compete for NIH and other research grants.

Data on the first three outcomes are reported in annual ADEA and ADA surveys. Data for the remaining outcomes were from three schools with the smallest increase in revenues and three schools with the largest increase in revenues from 1994 to 2003. For each of the six schools, the full-time clinical faculty listed in the ADEA faculty survey were identified at two points in time, and these faculty were then checked against the ADA master list of dentists to obtain data on the variables of interest. The latter includes all dentists in the United States who are in private practice or employed in private or public organizations involved in dental activities. Both licensed and nonlicensed dentists are listed, and the dental school, advanced training, specialty board status, current employment, and graduate degrees are noted. The rationale for limiting the analysis to schools with the lowest and highest growth in revenues was because these were the schools most likely to show the impact of reduced (increased) revenues on faculty recruitment and retention and because the data collection process was too labor-intensive to include all schools.

Student Diversity and Career Choice. To assess the impact of increasing tuition, fees, room and board, and other educationally related expenses, three outcomes were examined: 1) the parental incomes of 
enrolled students in all schools from 1992 to 2002; 2) the number (percentage) of underrepresented minority students enrolled in all dental schools; and 3) the career choices of graduates relative to their concerns about educational debt.

Condition of Physical Plants. There are no published data on the status of dental school physical facilities. As such, trends in physical plant operational budgets per state-supported school were adjusted for changes in the consumer price index (CPI). Presumably, physical plant expenditures should at least keep pace with increases in the CPI. Expenditures by state-supported dental schools were also compared to those by state-supported medical schools. Since, on average, state medical schools only receive 14 percent of their revenues from state funds (compared to 38 percent for state-supported dental schools), they are better positioned financially to deal with reductions in state funds. As such, average physical plant expenditures per medical school were expected to increase at a faster rate than at dental schools.

Research Universities. The capacity of dental schools to meet the academic mission of research universities was measured two ways: 1) the percentage of dental schools located among the Carnegie Foundation's top-rated research universities (Research Extensive Universities) from 1980 to 2005, and 2) the percentage of full-time faculty with funded NIH grants in 2003. The rationale for the first measure is the substantial literature that indicates the social status of different health profession occupations is partly a function of the number of required years of science-based education and training in research universities and their affiliated clinical settings and the commitment of faculty to the generation of new knowledge used in the education of students and the advancement of patient care..$^{20}$

Dental schools located in research universities must have credible research programs to meet the mission of their parent universities. Since no national ranking of dental school research programs is published, the only reliable data available were reports from the NIH on research grant awards to dental schools. Using the 2003 report, differences among state-supported schools in number of faculty were taken into account by determining the percentage of faculty with an award. The best available relative measure of faculty size is the number of full-time clinical faculty. Schools vary greatly in how they define and report basic science faculty, which makes these numbers unreliable. The NIH research awards measure has limitations: it does not control for variation among schools in accounting for research awards to basic science faculty shared by medical and dental schools; it does not include research awards from other organizations; it does not include training grants; and it assumes that faculty members have only one NIH research grant award.

Since the number of NIH research awards to schools is on a continuum, the minimal number needed for a sustainable research program had to be determined. Recommendations provided to us by experienced researchers and NIH administrators suggested that the number of NIH research grant awards per school should equal or exceed 10 percent of the number of full-time clinical faculty. For the average dental school with sixty-five full-time clinical faculty members, this means that they need at least six NIH grants for a viable research program.

\section{Results}

\section{Income Differences}

Figure 1 presents the average income of private practitioners in part- or full-time general dentistry and specialty practices and of full-time associate professors in general/restorative dentistry and specialty departments in all dental schools for the period 1990 to 2002 (actual data) and 2005 to 2015 (projected data). As expected, specialists in practice and dental school had higher incomes than their generalist colleagues. In 1990 the average income differences between generalists and specialists in private practice and dental schools were $\$ 26,000$ and $\$ 67,000$, respectively. By 2000 , these differences grew to $\$ 86,000$ and $\$ 170,000$, and by 2015 they are projected to be $\$ 278,000$ and $\$ 454,000$.

The impact of declining resources on dental school operations (all schools) is seen in Table 2. The time trend in dental students per full-time clinical faculty indicates fewer full-time clinical faculty in 1991-92 (3.82) compared to 2002-03 (4.26) - about a 12 percent decline. The reduction is mainly the result of increasing dental student enrollment rather than a decline in the absolute number of full-time clinical faculty.

At the same time, the percentage of FTE parttime clinical faculty to total FTE clinical faculty remained about the same: 20 percent. Table 2 also shows the modest increase in the number of unfilled FTE clinical positions: 4.5 percent in 1991-92 to 5.2 percent in 2003-04. 


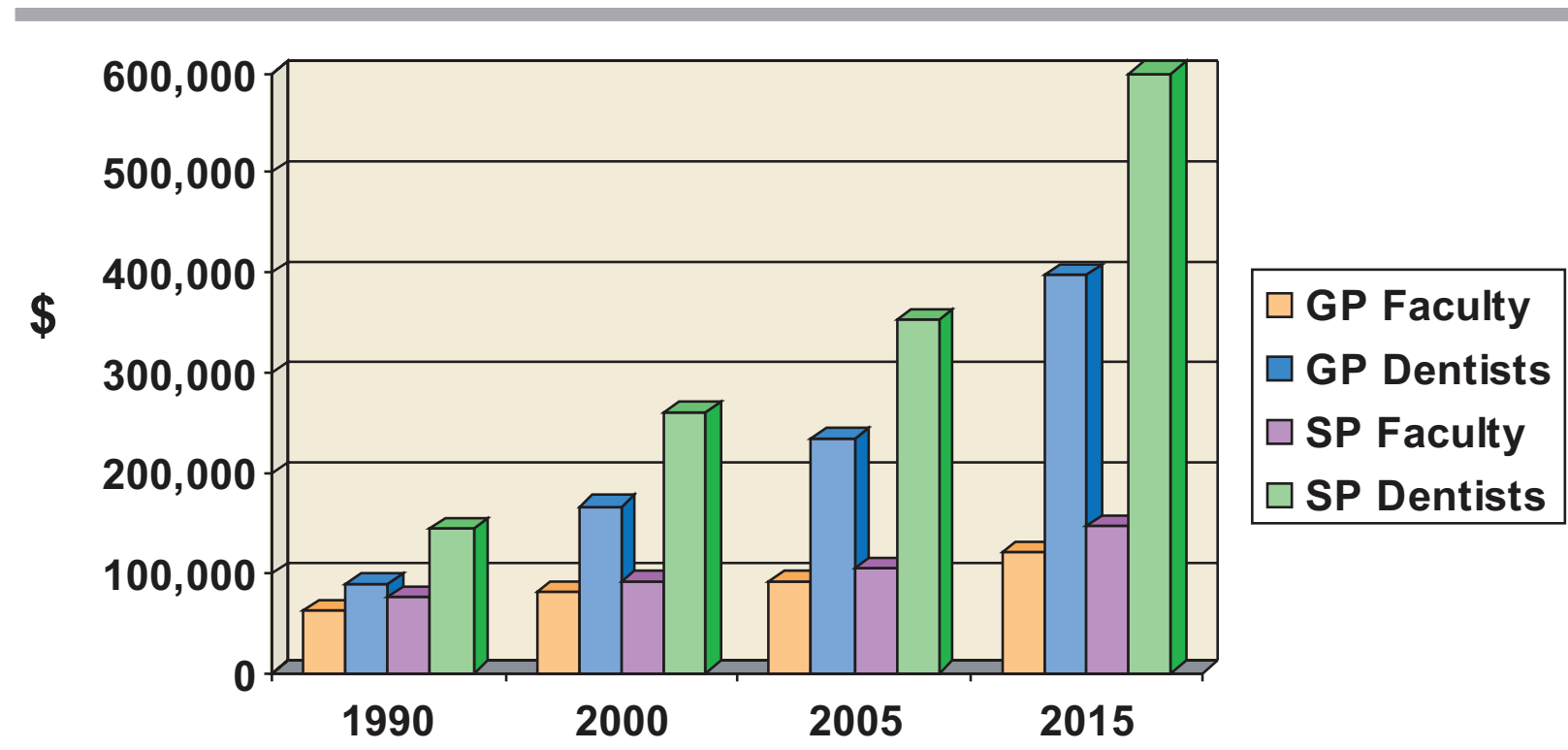

Figure 1. The actual (1990-2002) and projected (2005-15) average annual incomes of general and specialty part- and full-time private practitioners and of full-time associate professors in all dental schools

Sources: American Dental Association Survey Center. Surveys of predoctoral dental education (1990/1 to 2002/3). Chicago: American Dental Association, 1990/1 to 2002/3; Weaver RG, Haden NK, Valachovic RW. Annual ADEA survey of dental school seniors: 2003 graduating class. J Dent Educ 2004;68:1004-27.

Table 3 compares changes in full-time clinical faculty characteristics in three schools with the lowest and highest increases in total revenues. Schools with the lowest increases in revenues (average increase of 9 percent in nominal dollars) experienced a 34.6 percent decline in full-time clinical faculty; a 35.7 percent decline in faculty who were board-eligible or certified; and a 64.7 percent drop in faculty who had both D.D.S. and Ph.D. degrees. (Since most dental school faculty are clinicians, adequate numbers of them need to have scientific training at the Ph.D. level if schools are going to make a significant contribution to the scientific mission of their parent research universities.) In contrast, schools with the highest increase in revenues (average increase of 133 percent in nominal dollars) showed positive but limited changes in these faculty measures.

Figure 2 gives the actual (1993 to 2002) and projected (2005 to 2015) increase in the total costs of a four-year dental education for resident and nonresident students in state-supported dental schools. The rate of growth per year is 5.03 percent for residents and 5.74 percent for nonresidents. In 1993, resident costs for a dental education were $\$ 39,786$; this increased to $\$ 65,520$ (64.7 percent) in 2002 . By 2015 the projected cost is $\$ 134,678$, a

Table 2. Trends in full-time clinical faculty recruitment in state-supported dental schools, 1991-92 to 2003-04

Variables

Time 1

Time 2

Dental students/full-time clinical faculty positions*

$\%$ FTE part-time to total FTE clinical faculty*

$3.82(1991-92)$

$20.67 \%(1991-92)$

$\%$ FTE clinical faculty positions unfilled, ${ }^{* * *}$

$4.54 \%(1992-93)$

$\begin{array}{rr}4.26 & (2002-03) \\ 20.46 \% & (2002-03) \\ 5.28 \% & (2003-04)\end{array}$

\footnotetext{
*Source: American Dental Association Survey Center. Surveys of predoctoral dental education (1990/1 to 2002/3). Chicago: American Dental Association, 1990/1 to 2002/3.

**Source: Weaver RG, Chmar JE, Haden NK, Valachovic RW. Dental school vacant budgeted faculty positions: academic year $2003-04$. J Dent Educ 2005;69(2):296-305.
} 
105.6 percent increase. For nonresidents in 2015, it is $\$ 267,913$.

This rate of increase in dental education costs is associated with significant changes in the socioeconomic class and racial diversity of the student body for all schools. (While some of this increase in the family incomes of students is likely the result of rapidly rising tuitions, some is the result of general wage inflation.) As seen in Table 4, from 1997 to 2003, the number of entering dental students from families with annual parental incomes of $\$ 100,000$ or

Table 3. Average percent change in full-time clinical faculty characteristics in schools with lowest (3) and highest (3) increases in total revenues, 1994 to 2003

Faculty Characteristic Lowest Increase Revenues

Highest Increase Revenues

\begin{tabular}{lcc}
\hline Number FT Clinical Faculty & $-34.6 \%$ & $3.1 \%$ \\
Board-Eligible/Certified & $-35.7 \%$ & $3.1 \%$ \\
D.D.S./Ph.D. Degrees & $-64.0 \%$ & $12.5 \%$
\end{tabular}

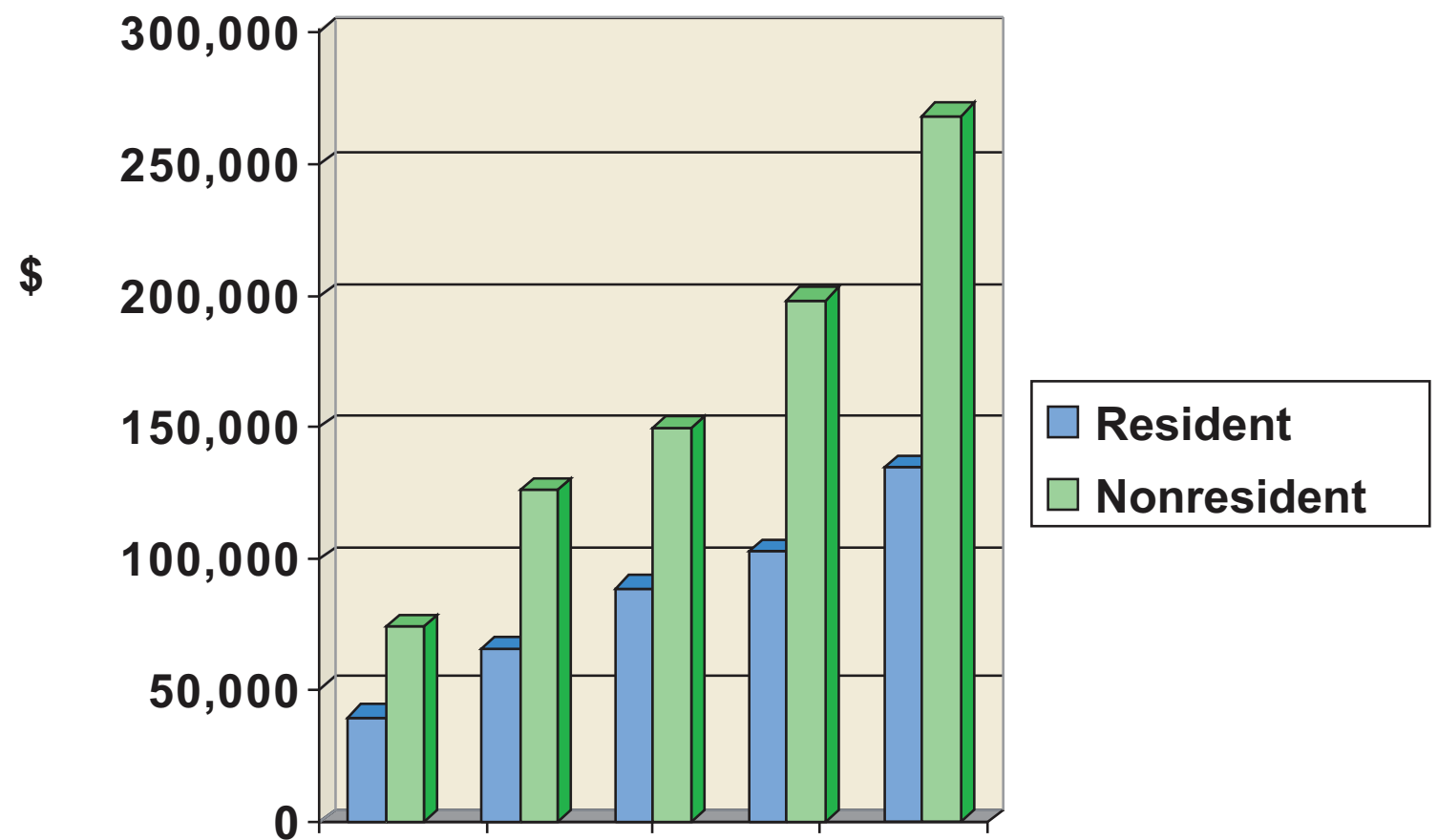

19932002200520102015

Figure 2. Resident and nonresident total four-year cost for a dental education in state-supported dental schools, 199394 to 2002-03 (actual) and 2005-15 (projected)

Source: American Dental Association Survey Center. Surveys of predoctoral dental education (1990/1 to 2002/3). Chicago: American Dental Association, 1990/1 to 2002/3. 
Table 4. Trends in dental student diversity, all dental schools, 1997 to 2003

\begin{tabular}{|c|c|c|}
\hline Variables & Time 1 & Time 2 \\
\hline \% Entering Students from Families with Parental Incomes $\$ 100 \mathrm{~K}$ or Greater & $32.4 \% \quad(1997-98)$ & $41.1 \% \quad(2002-03)$ \\
\hline \% Entering Students from Families with Parental Incomes $\$ 50 \mathrm{~K}$ or Less ${ }^{*}$ & $31.4 \% \quad(1997-98)$ & $(2002-03)$ \\
\hline Underrepresented Minority Students** & $2,247 \quad(1990-91)$ & $(2000-01)$ \\
\hline
\end{tabular}

*Source: Weaver RG, Haden NK, Valachovic RW. Annual ADEA survey of dental school seniors: 2003 graduating class. J Dent Educ 2004;68:1004-27.

**Source: Sinkford JC, Valachovic RW, Harrison SG. Underrepresented minority dental school enrollment: continued vigilance required. J Dent Educ 2004;68(10):1112-8.

debt were significantly less interested in careers in academics/research/administration, advanced education, or solo private practice.

Figure 3 presents the annual average per dental and medical school physical plant operational expenditures (excludes capital investments) from 1990 to 2002, adjusted for inflation. State-supported dental schools decreased their real average expenditures from 1990 to 2000 by almost $\$ 400,000$. In 2002, the average increased modestly. Expenditures by statesupported medical schools show a much different picture. First, medical schools spend much more than dental schools on their facilities. This is expected, since they are much larger operations and include a basic science faculty with extensive research laboratories. Second, in contrast to dental schools, the average state-funded medical school physical plant expenditures grew much faster than the rate of inflation (\$6.2 million to $\$ 12.3$ million). Evidently, since on average only 14 percent of total revenues in state-supported medical schools comes from state funds (versus 38 percent for dental schools), they were not constrained by reductions in state budgets from making large investments in maintaining their physical facilities.

The strategic outcome is the place of dental schools in research universities. Currently, 80 percent of the thirty-six state-supported U.S. dental schools are located in the top tier of research universities (i.e., Carnegie Foundation-defined research extensive universities). Over the past twenty-five years, seven dental schools - all privately sponsored - have closed, and five were in this class of top research universities. Three new dental schools have opened in the past five years; none are located in a major research university. Overall, the percentage of state-supported dental schools in research extensive universities in 2005 (80 percent) is only slightly smaller than in 1980 (83 percent).

Figure 4 presents the distribution of state-supported dental schools (2003) by the percentage of full-time faculty with NIH research awards. Fourteen schools (39 percent) have less than 9 percent of full-time faculty with a grant from the NIH. At the other extreme, seven schools (19 percent) have 30 percent or more faculty with NIH grants. More than 50 percent of schools have at least 10 percent of their full-time faculty with an NIH research grant.

\section{Discussion}

The primary findings from these analyses are that, on average, state-supported dental schools are increasingly challenged to generate enough net revenues to make full-time clinical faculty salaries

Table 5. Percentage of graduating seniors, all schools with different career plans by concern with debt, 2002-03

\begin{tabular}{lcccc} 
Immediate Career Plans & Debt a Major Factor & Debt a Factor & Debt Not a Factor & Significance \\
\hline Teaching, Research, Administration & $14.3 \%$ & $30.0 \%$ & $55.7 \%$ & .01 \\
Advanced Education & $9.8 \%$ & $37.8 \%$ & $52.4 \%$ & .01 \\
Solo Private Practice & $19.5 \%$ & $39.6 \%$ & $40.9 \%$ & .01
\end{tabular}

Source: Weaver RG, Haden NK, Valachovic RW. Annual ADEA survey of dental school seniors: 2003 graduating class. J Dent Educ 2004;68:1004-27. 


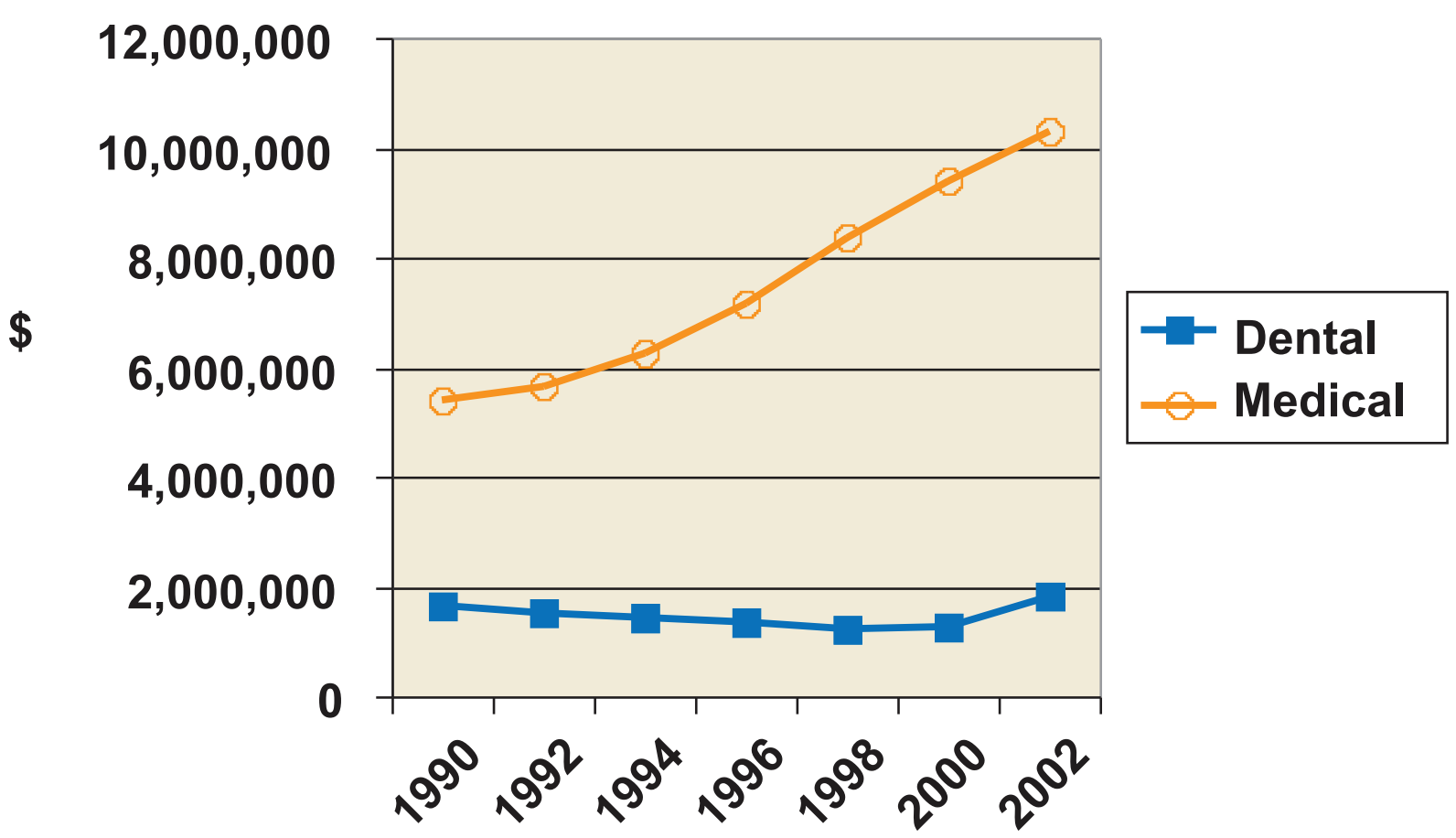

Figure 3. Average per school annual physical plants expenditures for state-supported dental and medical schools, 1990 to 2002 , adjusted for inflation

Sources: American Dental Association Survey Center. Surveys of predoctoral dental education (1990/1 to 2002/3). Chicago: American Dental Association, 1990/1 to 2002/3; Association of American Medical Colleges. Special analysis prepared by Ms. Donna Williams, Manager, Medical Profile System, Association of American Medical Colleges, July 2005.

reasonably competitive with private practitioner incomes, to keep tuition increases in line with the growth of the consumer price index, or to increase physical plant budgets at the rate of inflation. The adverse impact of these financial problems on dental school operations is evident in selected areas. The data indicate an increase in the number of students per full-time clinical faculty member. However, the percentage of FTE part-time clinical faculty and the increase in open clinical faculty positions changed very little from 1991-92 to 2003-04. Yet, for three schools with the lowest and three with the highest increases in total revenues from 1994 to 2003, the impact on full-time clinical faculty was dramatic. The schools with the lowest revenue increase lost a third of their full-time clinical faculty and a disproportionately higher percentage of clinical faculty with Ph.D. degrees. (The rationale for looking at changes in the number of clinical dental faculty with scientific training at the Ph.D. level is based on the fact that the great majority of faculty in dental schools have dental degrees. If dental schools are going to contribute significantly to the scientific mission of the university, significant numbers of clinical faculty must have the training to function as independent investigators.) These reductions are almost certain to have a negative impact on the quality of education and the schools' ability to meet the research mission of their parent universities. Indeed, the three schools with the lowest increases in total revenues experienced a 19.6 percent decline in external research funding over a ten-year period.

These findings are supported by information obtained in informal discussions with deans and department chairs. That is, it is becoming more difficult to recruit North American-educated faculty who have the scientific training to contribute to the research mission of the university.

Supporting evidence also comes from a recent ADEA report that found most new faculty are coming from private practice, are recent dental school graduates, and are armed forces retirees. ${ }^{5}$ Although these 


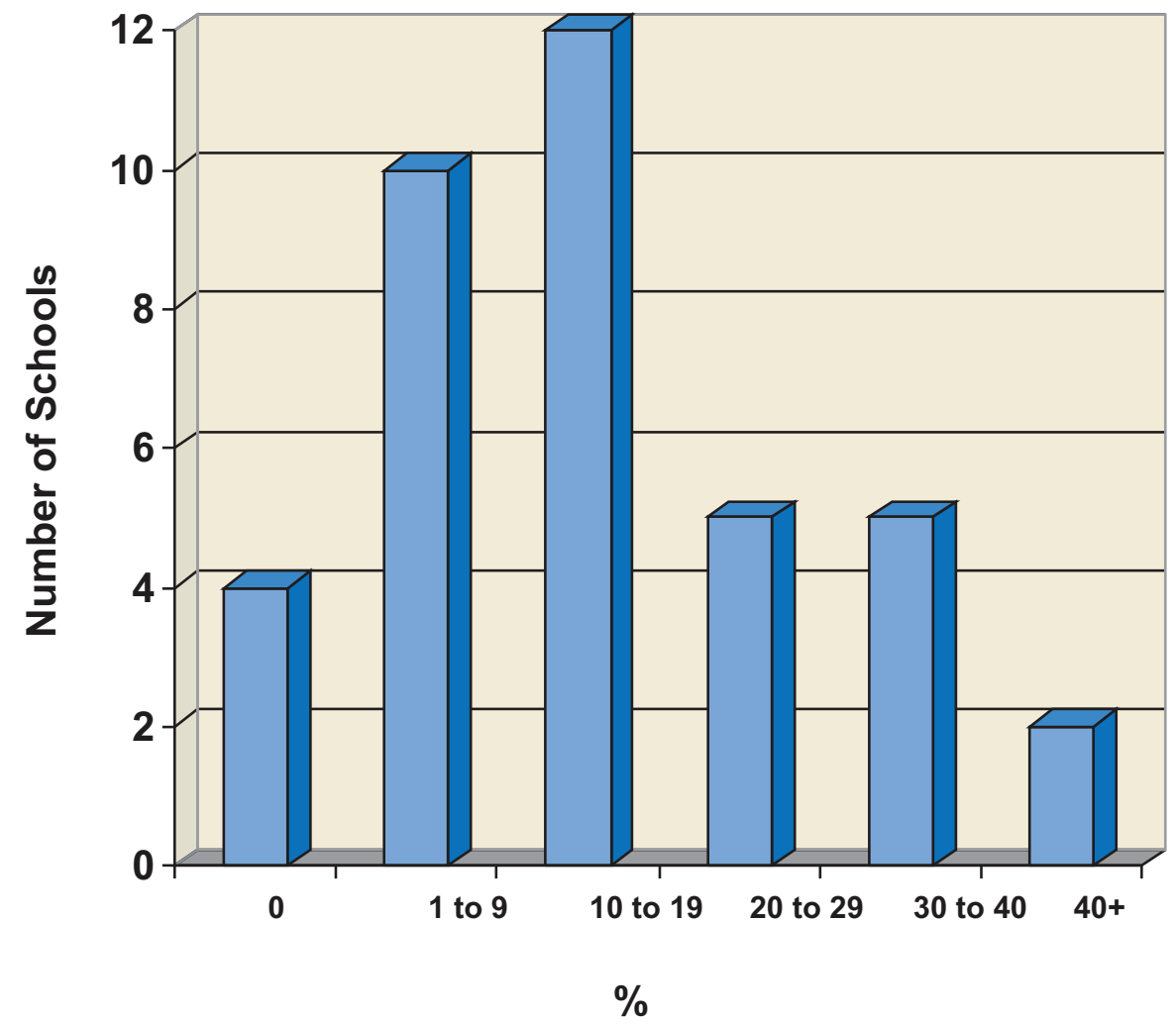

Figure 4. Percentage of full-time, state-supported dental school clinical faculty with NIH research grants, 2002-03

Source: National Institutes of Health. NIH awards to health professional components, fiscal year 2003: schools of dentistry, 2005. At: http://grants2.nih.gov/grants/award/trends/dhedento3.htm. Accessed: July 2005.

faculty can and undoubtedly do make a contribution to clinical teaching programs, many may not have the research training to provide students and residents with cutting-edge knowledge in their discipline, to advance the science of pedagogy, or to meet the research mission of dental schools in Carnegie research extensive universities.

Of great concern, the ten-year projections indicate that at the current rate of growth for differences between clinical faculty and private practitioner income will soon exceed $\$ 100,000$ for generalists and $\$ 200,000$ for specialists. These differences are so large that most schools may not be able to recruit and retain adequate numbers of well-qualified faculty educators and researchers who are licensed to practice in the United States. This problem is exacerbated by the fact that large numbers of dental faculty are expected to retire in the next five years. ${ }^{22}$

The continued rapid rise of tuition, fees, and other expenses associated with dental education brings another set of challenges to schools. With a median per family annual income of $\$ 51,407$ (2001) ${ }^{23}$ the great majority of American families are unable to contribute significantly to the support of their children's dental education. This suggests that the trend for more students to come from families in the upper tenth percentile of income will continue. The high cost of dental education will become an even greater barrier for disadvantaged students who want to pursue a career in dentistry.

Of equal concern is the dramatic impact that concern with debt is having on the career choices of graduates. Those greatly concerned with debt are less interested in solo practice, advanced clinical training, and academic careers. As debt increases, this could lead to a significant decline in the percentage of dentists in solo and two-person practices and may also reduce the number of graduates willing to treat underserved patients.

Slowly increasing physical plant budgets are also a significant problem. Most schools are not even able to keep physical plant operational expenditures 
at the rate of inflation. In contrast, state-supported medical school physical plant budgets are rising much faster than the consumer price index. Clearly, dental schools must be deferring needed maintenance and improvements, and this problem is certain to become more acute since many dental schools are thirty to forty years old. The paucity of available information on this issue limits greater understanding of the problem. ADEA needs to take immediate steps to develop a database on the physical condition of dental school facilities.

The capacity of dental schools to meet the mission of research universities is another important issue. Compared to 1980, about the same percentage of state-supported dental schools are now located in the top tier of research universities. Also, for these schools, more than half have a reasonable number of $\mathrm{NIH}$-funded research grants. However, there is little reason to be complacent. If the twelve schools that have 10-19 percent of their faculty with NIH research lost one or two faculty with research grants, only 25 percent of state-supported dental schools would have viable research programs.

\section{Conclusion}

This article demonstrates that state-supported dental schools are faced with significant challenges. Although data from the last ten years indicate that certain operational and strategic indicators are moving in the wrong direction, it may be premature to conclude that there is a "crisis" in dental education. While probably true for selected schools, the term "crisis" does not apply to the overall system. However, if current trends continue for the next ten years, there is little doubt that the term "crisis" will describe the situation faced by dental schools. Further, assuming that it will take at least ten or even more years to address and resolve these financial problems, now is the time for dental educators, practitioners, and other interested parties from the private and public sectors to come to a consensus on how to deal with the coming crisis. Clearly, these financial problems will not be solved by minor adjustments to the curriculum, modest improvements in the clinical productivity of students or faculty, or even significant increases in contributions from alumni.

The solutions must involve basic structural changes in the way dental education is financed and organized. At minimum, resources must become available to provide full-time clinical faculty with competitive incomes and to provide them with the scientific and educational training to make scholarly contributions to the educational and research missions of top-tier research universities. A career in academic dentistry must become more attractive and exciting to the "best and brightest" in the dental profession. Likewise, the rate of increase in the cost of a dental education needs to slow, and funds are needed to invest in aging facilities.

If these financial problems are not successfully resolved in the next ten years, the place of dental education in research universities is likely to be seriously threatened, as is the professional status of dentistry as a separate but equal health profession to medicine. Some key signals indicating that things are moving in the wrong direction will be the closure of more dental schools in research universities and the opening of new schools by for-profit and other non-research-oriented institutions.

Needless to say, the issues discussed here are complex, and there are no simple and easy answers. It is times of great challenge that require great leaders to step forward and build the political consensus needed to develop new and more effective strategies to educate the next generation of American dentists and to keep dental education based in research universities. The future of the dental profession and the oral health of the American people depend on it.

\section{REFERENCES}

1. Bailit H, Weaver R, Haden K, Kotowicz W, Hovland E. Dental education summit: the challenges ahead. J Am Dent Assoc 2003;137:1109-13.

2. Bailit H, Beazoglou T. State financing of dental education: impact on supply of dentists. J Dent Educ 2003;67(12):1278-85.

3. National Conference of State Legislatures. States' fiscal supports for higher education improves after two-year drought. NCSL News 2004. At: www.ncsl.org/programs/ press/2004/pr040915a.htm. Accessed: July 2005.

4. Haden NK, Weaver RG, Valachovic RW. Meeting the demands for future dental school faculty: trends, challenges, and responses. J Dent Educ 2002;66(9):1102-13.

5. Weaver RG, Chmar JE, Haden NK, Valachovic RW. Dental school vacant budgeted faculty positions: academic year 2003-04. J Dent Educ 2005;69(2):296-305.

6. Introductory comments by Robert Anderton, President of the American Dental Association, at the Dental Educational Summit held in Chicago, July 2001.

7. DePaola DP, Slavkin HC. Reforming dental health professions education: a white paper. J Dent Educ 2004; 68(11):1139-50.

8. American Dental Association. Dental education forum to examine crisis. ADA News. 7/13/2004. At: www.ada. 
org/prof/resources/pubs/adanews/adanewsarticle.asp? articleid=967. Accessed: July 2005.

9. American Association of Dental Schools. Report of the AADS Presidential Task Force on Future Dental School Faculty. August 13, 1999. At: www.adea.org/DEPR/ future\%20faculty.pdf. Accessed: July 2005.

10. American Dental Association Survey Center. Surveys of predoctoral dental education (1990/1 to 2002/3). Chicago: American Dental Association, 1990/1 to 2002/3.

11. American Dental Education Association, Division of Educational Policy and Research. Faculty salary survey summary report: guaranteed annual salary (2001/2) and total compensation (2001/2). Washington, DC: American Dental Education Association, 2003.

12. Weaver RG, Haden NK, Valachovic RW. Annual ADEA survey of dental school seniors: 2003 graduating class. J Dent Educ 2004;68:1004-27.

13. American Dental Association Survey Center. Survey of dental practice (1990 to 2002). Chicago: American Dental Association, 1990 to 2002.

14. Association of American Medical Colleges. Special analysis prepared by Ms. Donna Williams, Manager, Medical Profile System, Association of American Medical Colleges, July 2005.

15. The Carnegie Foundation for the Advancement of Teaching. Doctoral/research universities-extensive: public institutions by state, 2005. At: www.carnegiefoundation.org/
Classification/CIHE2000/Partfiles/DRU-EXT.htm. Accessed: July 2005.

16. National Institutes of Health. NIH awards to health professional components, fiscal year 2003: schools of dentistry, 2005. At: http://grants2.nih.gov/grants/award/trends/dhedento3.htm. Accessed: July 2005.

17. Nash KD, Brown JL. Rate of return from a career as dental school faculty. In: Meskin LH, Brown LJ, eds. The economics of dental education. Chicago: American Dental Association, Health Policy Resources Center, 2004:41-78.

18. Heffler S, Smith S, Keehan S, et al. Health spending projections through 2013. Health Affairs (web exclusive) 2004;11(4):79-93.

19. Bailit HL. Dental insurance, managed care, and traditional practice. J Am Dent Assoc 1999;130:1721-7.

20. Freidson E. Profession of medicine. New York: Harper \& Row, 1970

21. Sinkford JC, Valachovic RW, Harrison SG. Underrepresented minority dental school enrollment: continued vigilance required. J Dent Educ 2004;68(10):1112-8.

22. Livingston HM, Dellinger TM, Hyde JC, Holder R. The aging and diminishing dental faculty. J Dent Educ 2004; 68(3):345-54.

23. U.S. Census Bureau. Median and average family incomes by family size, U.S., 1947-2001. Washington, DC: U.S. Department of Commerce, 2005. At: www.usc.edu/schools/ $\mathrm{sppd} / \mathrm{research} / \mathrm{casden} / \mathrm{research} / \mathrm{data}$ folder/us faincsize.pdf. Accessed: July 2005. 